\title{
Concomitant infection of Coccidiosis and Capillariasis in Fancy Pigeons (Columba livia) - A Case Report
}

\author{
S. Ramesh ${ }^{1}$, C. Soundararajan ${ }^{3}$, S. Subapriya ${ }^{2 *}$, R. Sokkalingam ${ }^{4}$ \\ and S. Muthukrishnan \\ ${ }^{1}$ Centralised Instrumentation Laboratory, ${ }^{2}$ Centralised Clinical Laboratory, \\ ${ }^{3}$ Department of Veterinary Parasitology, Madras Veterinary College, Chennai-07, India \\ ${ }^{4}$ Society for the Prevention of Cruelty to Animals (SPCA), Chennai-07, India \\ ${ }^{5}$ Departmentof Veterinary Anatomy, Veterinary College and Research Institute, \\ Tirunelveli, India \\ *Corresponding author
}

\begin{abstract}
A B S T R A C T
Keywords

Pigeon- coccidiosis and capillariasis

Article Info

Accepted:

30 November 2018

Available Online:

10 December 2018

Two adult fancy pigeons which were presented to SPCA hospital, Chennai were referred for clinical diagnosis with the history of dullness, anorexia and intermittent diarrhoea. Coproscopic examination revealed the presence of oocysts of Eimeria spp and eggs of Capillaria spp. The birds became normal and active after ten days post treatment with pyrantel pamoate (as a single dose and repeated after 14 days) and amprolium for 5 days.
\end{abstract}

\section{Introduction}

The domestic pigeons (Columba livia), belonging to family Columbidae, virtually found in every town and city around the world are mostly bred for hobby. They transmit many of the diseases including parasitic diseases to humans as well as other mammals and birds either directly or indirectly through the infected droppings (Marques et al., 2007). Although they are hardy birds, they succumb to variety of infectious agents like other avian species (Ghazi et al., 2002). Despite the many clinical cases, little has been documented about the incidence of endoparasites in caged and wild birds (Sprenger et al., 2018). Thus the present paper reports an incidence of concomitant infection of coccidiosis and capillariosis in two fancy pigeons.

\section{Materials and Methods}

Two adult pigeons which were presented to SPCA hospital were referred for clinical diagnosis with the history of dullness, anorexia and intermittent diarrhoea. A thorough physical examination was carried out on both the birds. The droppings voided by the birds were collected and subjected to parasitic examination. Based on laboratory findings, the 
birds were treated with pyrantel pamoate (@ $5 \mathrm{mg} / \mathrm{kg}$ as a single dose and repeated after 14 days and amprolium soluble powder @ 5 gm per litre of water for 5 days.

\section{Results and Discussion}

Physical examination of the two pigeons revealed no abnormalities except dullness (Fig. 1). The droppings voided by the birds were greenish white with red tinged and watery in consistency. Coproscopic examination revealed the presence of oocysts of coccidia and eggs of Capillaria spp. Based on the morphological characters the eggs were confirmed as Eimeria spp and Capillaria spp. Oocysts of Eimeria were ovoid to ellipsoid in shape (Fig. 2) while the eggs of Capillaria were lemon-shaped, yellowish in color, with thick, punctate shells provided at either end with a "plug" (Fig. 3). The bird became active and alert with normal feeding habit after ten days of treatment.

Mohammed et al., (2017) examined 144 intestinal contents of pigeons and recorded an overall prevalence of $19.44 \%$ of coccidiosis. The prevalence was higher in females
(20.83\%) than males (18.06\%). Furthermore, squabs had the highest prevalence $(27.08 \%)$ followed by squeakers (20.83\%), and youngsters (10.42\%). Infection with Eimeria spp oocysts was higher during the wet season $(8.96 \%)$ than dry season (5.98\%). Out of 370 faceal samples of pigeons examined, 121 samples were found to be positive for Eimeria spp (32.7\%) (Kommu et al., 2016). Marques et al., (2007) reported an incidence of 86.05 $\%$ of Eimeria spp in free living pigeons.

Mohammed et al., (2017) examined the intestinal contents of 144 pigeons for a period of six months and recorded an incidence of $7.63 \%$ of Capillariasis. Infection rate was higher in males $7(9.72 \%)$ than females 4 $(5.55 \%)$ pigeons. There were no significant sex related differences seen in the prevalence of $C$. obsignata. Among the pigeons examined only the youngsters were found to be infected. Kommu et al., (2016) examined faceal samples of 370 pigeons and found 16 samples were positive for Capillaria spp (4.32\%). Marques et al., (2007) reported a prevalence of $21.42 \%(3 / 14)$ of Capillaria spp in free living pigeons.

Fig.1 Fancy pigeons - Dullness

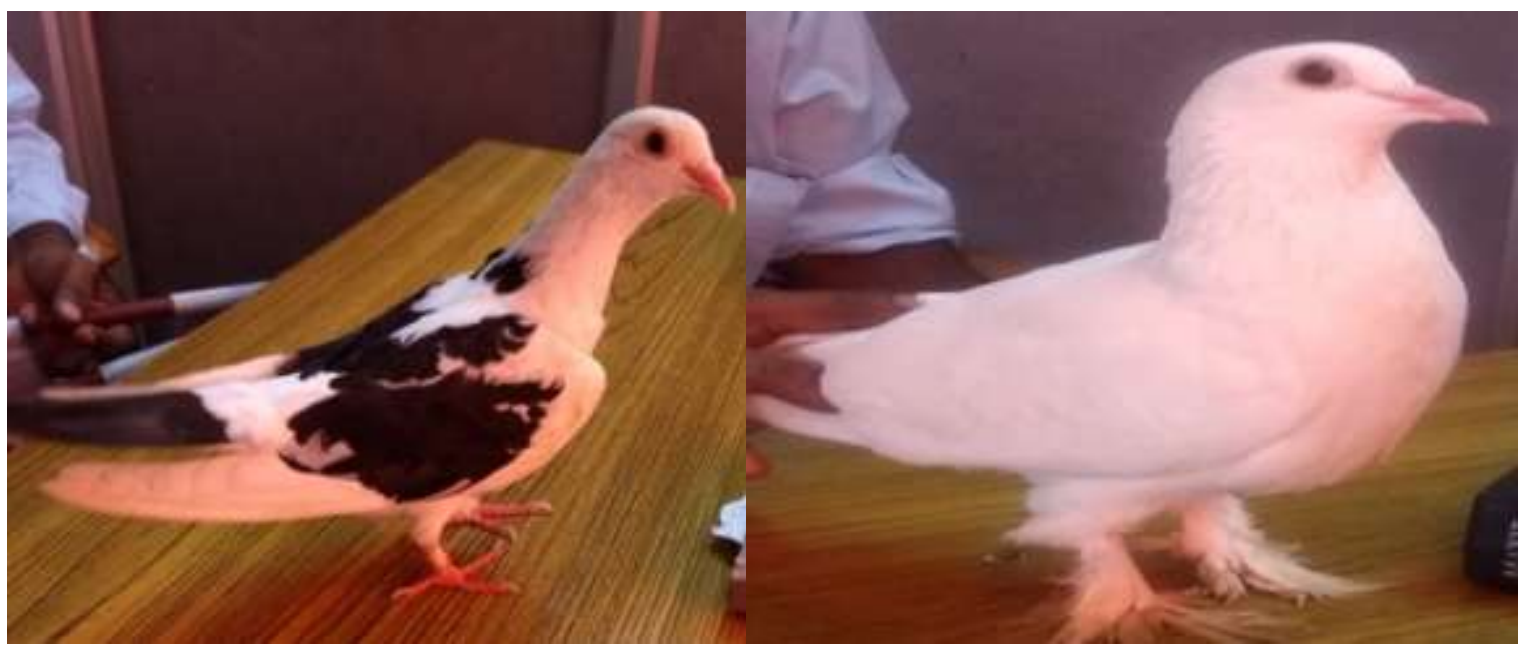


Fig.2 Pigeon- Eimeria Oocyst

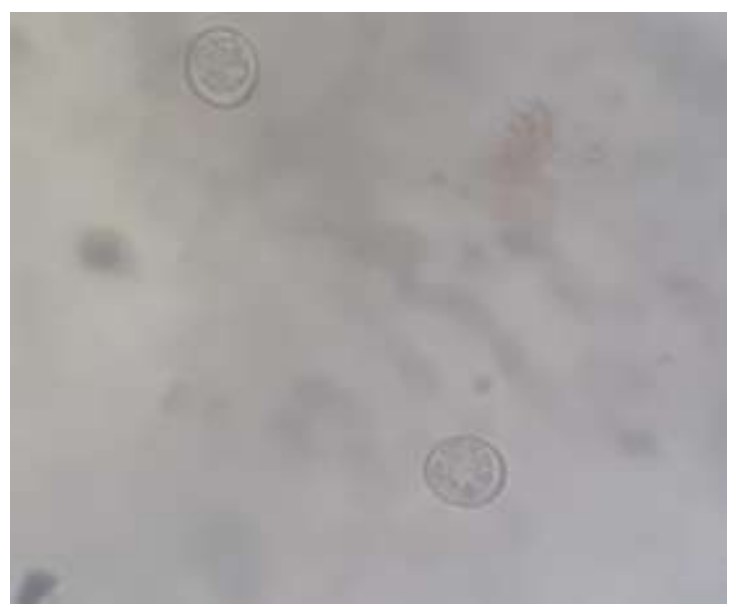

Ramesh et al., (2015) reported an incidence of cestodiasis in a Blue Rock Pigeon and the tape worm was identified as Cotugnia spp. Ascaridia spp was commonly detected in faecal samples of wild birds followed by Capillaria spp. and Heterakis spp (Hoque et al., 2014). Sivajothi and Sudhakara Reddy (2015) reported $72.7 \%$ of domestic pigeons harbored parasites including Ascaridia colombae (33.3\%), Eimeria spp (31.0\%), Capillaria colombae (17.4\%) and Raillietina $(9.0 \%)$. Most of the pigeons were more likely to harbor mixed infections (31.8\%). They also opined that there was a relation between the occurrences of gastrointestinal parasitic infections with the age of the pigeons which showed that high prevalence in adults (75\%) when compared to squabs $(64.2 \%)$.

Treatment options for all nematodes include ivermectin, fenbendazole, piperazine, pyrantel pamoate, or levamisole hydrochloride. Treatment choice will depend on the parasite identified and the passerine species affected, as well as on safety and efficacy data (Hoque et al., 2014).

\section{References}

Hoque M.A., Hassan M.M., Haque E, Shaikat A.H., Khan S.A., Alim A, Skerratt L.F.,
Fig.3 Pigeon-Capillaria egg

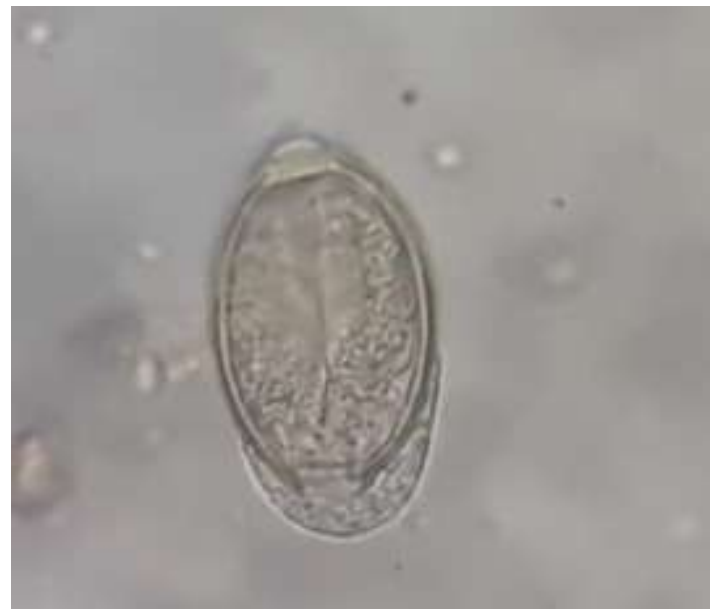

Islam A, Tun H.M., Dissanayake R, Day T.K., Debnath N.C., Yamage M. 2014. A survey of gastro-intestinal parasitic infection in domestic and wild birds in Chittagong and Greater Sylhet, Bangladesh. Prev Vet Med., 117(1):305-12

Kommu S, Rajeshwari G, Sreenivasamurthy G.S. 2016. Prevalence of helminthic and protozoan infections in pigeons- in and around Hyderabad of Telangana state 1(1): 1-3

Marques, S.M., De Quadros, R.M., Da Sailva, C.J. and Baldo, M. (2007). Parasites of pigeons (Columba livia) in urban areas of Lages, Southern Brazil. Parasitol. Latino Amr., 62: 183-187.

Mohammed, B.R., Simon, M.K., Agbede, R.I. and Arzai, A.H., 2017. Coccidiosis of domestic pigeons (Columba livia domestica Gmelin, 1789) in Kano State, Nigeria. Annals parasitology, 63(3):199-203.

Rabiu, M.B., Kawe, S.M., Shehu A.R.I and Haruna, A.A. 2017. Detection of Capillaria obsignata of Pigeons (Columba livia domestica) from Kano State, Nigeria. Research Journal of Parasitology Pp.1-5

Ramesh, S, Balachandran, C., Vijayarani, K., Latha, B.R., Kavitha, K.T., 
Palanivelrajan, M., Senthilkumar, K, Savithri, M, Pazhanivel, $\mathrm{N}$ and Jayathangaraj, M.G. 2015. Concurrent Marek's Disease and Cestodiasis in a Blue Rock Pigeon (Columbia livia). The Indian Vet J., 92(5): 85-86.

Sivajothi and Reddy, S. 2015. A study on the gastro intestinal parasites of domestic pigeons in YSR Kadapa district in Andhra Pradesh, India. J Dairy Vet Anim Res., 2(6): 216-218.

Sprenger L. K., Ursula, Yoshitani, Buzatti, A and Molento, M.B. 2017. Occurrence of gastrointestinal parasites in wild animals in State of Paraná, Brazil. An Acad Bras Cienc., 90(1): 231-238

\section{How to cite this article:}

Ramesh, S., C. Soundararajan, S. Subapriya, R. Sokkalingam and Muthukrishnan, S. 2018. Concomitant infection of Coccidiosis and Capillariasis in Fancy Pigeons (Columba livia) - A Case Report. Int.J.Curr.Microbiol.App.Sci. 7(12): 3701-3704.

doi: https://doi.org/10.20546/ijcmas.2018.712.421 